\title{
Effects of climate change on US crop production: simulation results using two different GCM scenarios. Part I: Wheat, potato, maize, and citrus
}

\author{
F. N. Tubiello ${ }^{1, *}$, C. Rosenzweig ${ }^{1}$, R. A. Goldberg ${ }^{1}$, S. Jagtap ${ }^{2}$, J. W. Jones ${ }^{2}$ \\ ${ }^{1}$ Columbia University and NASA-Goddard Institute Space Studies, Armstrong Hall, 2880 Broadway, New York, \\ New York 10025, USA \\ ${ }^{2}$ College of Agricultural and Life Sciences, University of Florida, PO Box 110270, Gainesville, Florida 32611, USA
}

\begin{abstract}
We projected US agricultural production in 2030 and 2090 at 45 representative sites, using 2 scenarios of climate change, developed with the Hadley Centre Model and the Canadian Centre Climate Model, and the DSSAT (Decision Support Systems for Agro-technology Transfer) dynamic crop-growth models. These simulation results have previously been aggregated nationally with the aid of economic models to show an increase in overall US agricultural output under climate change. In this work, we analyzed the regional distribution of the simulated yields, showing that positive results largely depend on the precipitation increases projected by the climate scenarios. In contrast, in some important rainfed production areas where precipitation was projected to decrease, such as the Kansas and Oklahoma Bread Basket regions under the Canadian Centre Climate Model scenario, climate change resulted in significant reductions of grain yield ( -30 to $-40 \%$ ), accompanied by increased year-to-year variability. We also discussed the response to additional factors affecting the simulated US crop production under climate change, such as higher temperature and elevated $\mathrm{CO}_{2}$.
\end{abstract}

KEY WORDS: Climate change $\cdot$ Agriculture $\cdot$ Elevated $\mathrm{CO}_{2} \cdot$ US National Assessment $\cdot$ Adaptation

\section{INTRODUCTION}

Simulations performed with state-of-the art general circulation models (GCMs) indicate that, if current patterns of world energy use are not modified, future increases in atmospheric greenhouse gas concentration will raise the mean annual global surface air temperature by 1.5 to $6^{\circ} \mathrm{C}$ by the end of this century, compared to the reference period 1960-1990 (Houghton et al. 1996).

Agricultural crop production is certainly going to be affected under future climate change. Even so, the magnitude and even the direction of climate impacts on crop yields will vary locally, because of regional dif-

*E-mail: franci@giss.nasa.gov ferences in both natural and anthropogenic factors that control plant response. For instance, elevated $\mathrm{CO}_{2}$ alone is expected to increase crop yields (Kimball 1983), but higher temperatures may act to either enhance or counterbalance this beneficial effect. Projected higher spring-summer air temperatures would be beneficial to crop production at northern sites, where the length of the growing season is currently a limiting factor to growth. By contrast, higher temperatures and increased water demands in southern regions may counteract $\mathrm{CO}_{2}$ effects and depress crop yields, particularly in marginal lands where water stress is already a problem (Rosenzweig \& Tubiello 1997). Changes in production due to climate change will also critically depend on crop management, such as the type and levels of applied irrigation and fertilization. Recent experiments have shown that crop 
response to elevated $\mathrm{CO}_{2}$ is relatively greater when water is a limiting factor, compared to well-watered conditions (Chaudhuri et al. 1990, Kimball et al. 1995). The contrary is true for nitrogen applications: wellfertilized crops respond more positively to $\mathrm{CO}_{2}$ than less fertilized ones (Sionit et al. 1981). Finally, $\mathrm{CO}_{2}$ will affect differently C3 (e.g. wheat, soybean, citrus) and C4 plants (e.g. maize, sorghum, plus several important agricultural weeds), as the latter group is less responsive than the former to increased $\mathrm{CO}_{2}$ levels in the atmosphere (Rosenzweig \& Hillel 1998).

Table 1. Simulation study sites, symbols, and crops simulated at each location

\begin{tabular}{|c|c|c|}
\hline Site & Symbol & Crops simulated \\
\hline 1. Abilene, TX & ABTX & Winter wheat, sorghum \\
\hline 2. Alamosa, CO & ALCO & Potato \\
\hline 3. Bakersfield, CA & BACA & Citrus, rice \\
\hline 4. Boise, ID & BOID & Winter wheat, spring wheat, potato \\
\hline 5. Buffalo, NY & BUNY & Potato, tomato \\
\hline 6. Caribou, ME & CAME & Potato \\
\hline 7. Columbus, $\mathrm{OH}$ & $\mathrm{COOH}$ & Tomato, winter wheat, maize \\
\hline 8. Columbia, SC & COSC & Soybean, sorghum, tomato \\
\hline 9. Corpus Christi, TX & CCTX & Citrus \\
\hline 10. Daytona Beach, FL & DBFL & Citrus \\
\hline 11. Des Moine, IA & DEIA & Maize, soybean \\
\hline 12. Dodge City, KS & DOKS & Winter wheat \\
\hline 13. Duluth, MN & DUMN & Maize, soybean \\
\hline 14. El Paso, TX & EPTX & Citrus, rice, sorghum, tomato \\
\hline 15. Fargo, ND & FAND & Spring wheat, potato, maize \\
\hline 16. Fresno, CA & FRCA & Rice, spring wheat, tomato \\
\hline 17. Glasgow, MT & GLMT & Spring wheat \\
\hline 18. Goodland, KS & GOKS & Winter wheat, sorghum \\
\hline 19. Indianapolis, IN & ININ & Potato, maize, soybean, tomato \\
\hline 20. Las Vegas, NV & LVNE & Citrus \\
\hline 21. Louisville, KY & LOKY & Soybean, sorghum \\
\hline 22. Madison, WI & MAWI & Potato, maize, soybean \\
\hline 23. Medford, OR & MEOR & Potato \\
\hline 24. Memphis, TN & METN & Maize, soybean \\
\hline 25. Miami, FL & MIFL & Rice, citrus \\
\hline 26. Montgomery, AL & MOAL & Citrus, rice, soybean, sorghum, tomato \\
\hline 27. Muskegon, MI & MUMI & Potato, soybean, tomato \\
\hline 28. North Platte, NE & NONE & Winter wheat, maize, soybean, sorghum \\
\hline 29. Oklahoma City, OK & OKOK & Winter wheat, sorghum \\
\hline 30. Pendleton, OR & PEOR & Potato \\
\hline 31. Peoria, IL & PEIL & Maize, soybean, sorghum \\
\hline 32. Pierre, SD & PISD & Spring wheat, sorghum \\
\hline 33. Port Arthur, TX & PATX & Rice, citrus \\
\hline 34. Raleigh, NC & RANC & Soybean, sorghum, tomato \\
\hline 35. Red Bluff, CA & RBCA & Rice, citrus \\
\hline 36. Savannah, GA & SAGA & Citrus, soybean, sorghum \\
\hline 37. Scott Bluff, NE & SBNE & Potato \\
\hline 38. Sioux Falls, SD & SFSD & Maize, sorghum \\
\hline 39. Shreveport, LA & SHLA & Rice, citrus \\
\hline 40. Spokane, WA & SPWA & Winter wheat, spring wheat \\
\hline 41. St. Cloud, MN & $\mathrm{SCMN}$ & Spring wheat, maize, soybean \\
\hline 42. Tallahassee, FL & TAFL & Citrus, tomato \\
\hline 43. Topeka, KS & TOKS & Winter wheat, maize, soybean, sorghum \\
\hline 44. Tucson, AZ & TUAZ & Spring wheat, citrus \\
\hline 45. Yakima, WA & YAWA & Potato \\
\hline
\end{tabular}

Because the combined influence of many relevant factors must be assessed to determine the full response of agricultural crops to future climate conditions, computer simulations have been used extensively to project potential impacts on agriculture (e.g. Rosenberg 1993, Rosenzweig \& Parry 1994).

This study evaluates the impacts of potential climate change on crop production in the United States. It was conducted as part of the US National Assessment (www.nacc.usgcrp.gov, Reilly et al. 2001). Previous studies have generally projected small negative to mildly positive changes in US crop yields due to the impacts of climate change and elevated $\mathrm{CO}_{2}$ (e.g. Easterling et al. 1993, Rosenzweig et al. 1995, Mearns et al. 1997, Rosenzweig \& Hillel 1998). The study presented herein adds to previous work by analyzing a larger number of sites, and by simulating more crops than done previously. It includes simple adaptation techniques, such as changes in planting date and of cultivar type, which may be needed to optimize crop yields under a future climate. Additionally, this work employs new climate scenarios, which are considered to be more realistic than those previously available. These new scenarios, provided by the US National Assessment, consider the cooling effects of sulfuric aerosols on surface air temperature, in addition to the warming due to greenhouse gases. As a result, these scenarios project temperature increases that are smaller than previously forecast for the first half of this century. By the end of the century, however, the 'masking' effects of sulfuric aerosols become small compared to greenhouse forcing, and projected temperature increases become substantial, with a warming for the US projected to be in the range of $3-5^{\circ} \mathrm{C}$ (US National Assessment 2000).

We note that crop simulation results should be regarded as defining at best upper limits to actual crop responses to climate change and elevated $\mathrm{CO}_{2}$. Crop models typically assume that soil nutrients and micro-nutrients are not limiting, and that pests (insects, diseases, weeds) pose no threat to crop growth and yield. It can be expected that in the field some or all of these missing factors may limit, or in some 
cases altogether modify, the crop response patterns that are computed by the models.

Finally, this study focuses on assessing the vulnerability of current agricultural production systems in the US under projected climate change. The reader should consider that such systems may be significantly different, and possibly more productive than at present, especially in the second half of this century, as farmers respond to evolving trends in international markets, land use patterns, and the emergence of new technology.

\section{MATERIALS AND METHODS}

\subsection{Site selection}

Based on US Department of Agriculture (USDA) national and state-level statistics (http://www.usda. gov/nass/), we chose 45 sites across the US, where we simulated, under both current and climate change conditions, production of 9 crops: wheat, maize, potato, citrus, soybean, tomato, sorghum, rice, and hay (Table 1). Results for the first 4 crops are analyzed in this work; all other crops, except hay, were analyzed in a companion paper (S. Jagtap et al. unpubl.). The simulation sites were chosen to represent areas of major crop production, and thus they did not span the US homogeneously (e.g. Fig. 1). Three sites for maize and 4 sites for citrus were intentionally selected at higher latitudes with respect to current production regions, to estimate the potential for northward shifts under climate warming. Finally, collection of weather data, crop management data, and calibration simulations at most sites had been performed in previous climate change modeling studies (Adams et al. 1990, Curry et al. 1995, Rosenzweig et al. 1995).

Readers interested in the full array of simulation results for each site and crop can consult a series of technical reports, available on the US National Assessment website (http://www.nacc.usgcrp.gov/sectors/ agriculture/working-papers.html).

\subsection{Generation of climate change scenarios}

We generated 5 climate scenarios at each site: a 'baseline' scenario, representing current climate conditions, and 4 scenarios of climate change. The latter were produced using the output of 2 GCMs, the Canadian Centre Climate Model scenario (CCGS) and the Hadley Centre Model scenario (HCGS), for 2 future time periods: '2030', representing the period 2020-2039, and '2090', representing the period 2080-2099. Atmospheric $\mathrm{CO}_{2}$ concentrations were specified for each period according to the 'business as usual' IPPC scenario (Houghton et al. 1996): $350 \mathrm{ppm}$ for the baseline; $445 \mathrm{ppm}$ for ' 2030 '; and 660 ppm for ' 2090 '. The 2 model scenarios and the 2 time periods chosen in this work had been specified within

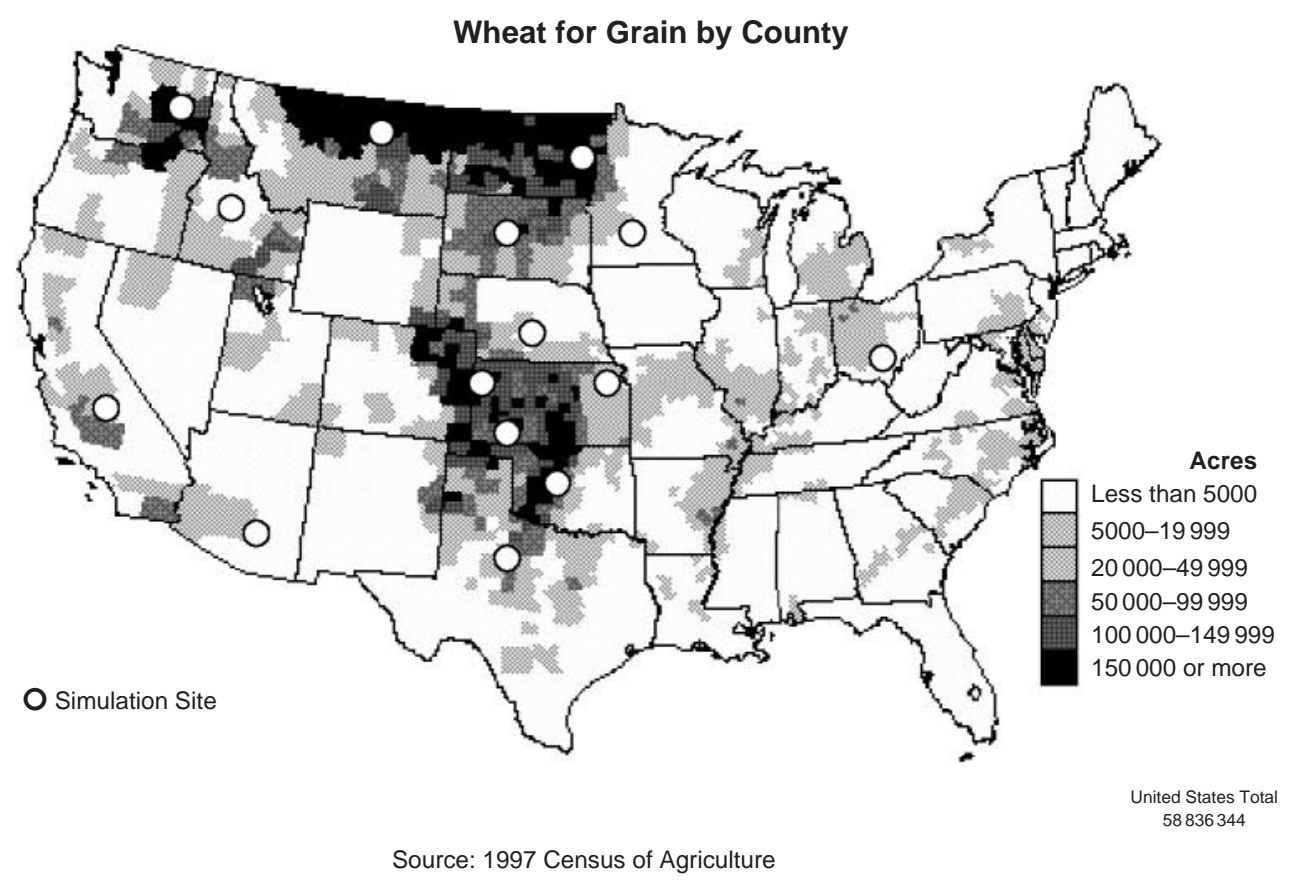

Fig. 1. Map showing wheat areas in the US, along with the simulation sites chosen to represent production 
the US National Assessment (2000) study. The 2 models were chosen to provide a range of variability in projected climate change, with contrasting regional forecasts, especially for precipitation. Specifically, over the 21st century the Hadley model projected increases in annual precipitation in the order of $20 \%$ across the US, with larger increases in southern California. By contrast, the Canadian Climate model projected increases in precipitation in the range 10 to $20 \%$ over the North-east and Corn Belt regions, but decreases of $-10 \%$ to $-20 \%$ over most of the Great Plains and California. The 2 study periods allowed researchers to assess the vulnerability of key sectors of the US economy in the near term, as a function of small initial climate changes (2030), as well as in the long term, under the impacts of a fully changed climate (2090).
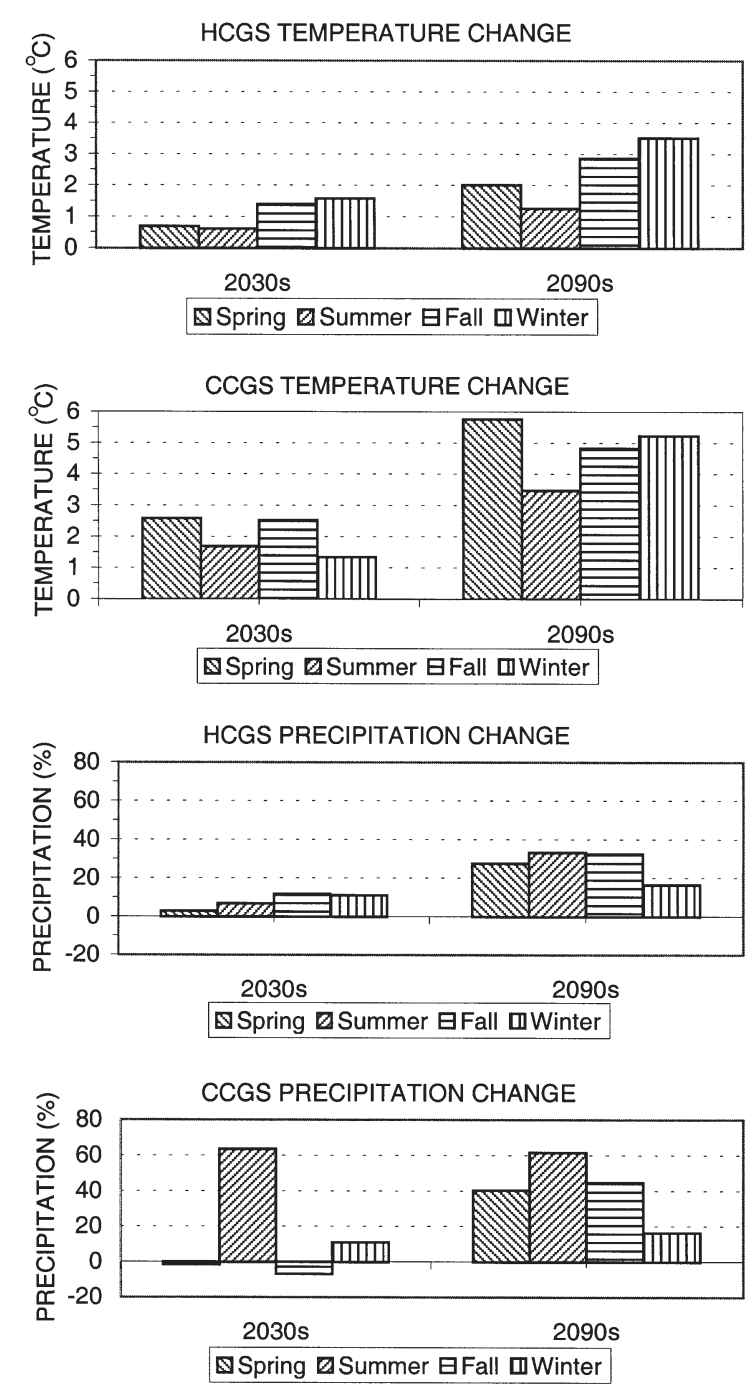

Fig. 2. An example of climate change conditions at Des Moines, IA, as predicted by the 2 climate change scenarios used in the National Assessment
The baseline scenario consisted of a complete $44 \mathrm{yr}$ data-set, containing the time series of observed daily temperatures (minimum and maximum), precipitation, and solar radiation for the period 1951-1994. These data have been collected and checked for errors over the past several years at NASA-GISS, as part of Climate Impacts group research activities (C.R. pers. obs.). The 4 climate change scenarios were generated as follows: For each specified time window (2030 or 2090), we applied to each daily quantity in the baseline period the corresponding (2020-2039 or 2080-2099) $20 \mathrm{yr}$ averaged changes specified by each scenario, computed on a monthly basis. In this way, new, $44 \mathrm{yr}$ long climate change series were generated, with mean values corresponding to the GCMs' projections, but with the same variability as the current climate. An example of the resulting climate change series for one of the study sites is given in Fig. 2, showing seasonal variations in the projected climate change.

We note that there is considerable uncertainty in the regional features of climate change projections made with GCMs, due to coarse spatial resolutions that often miss specific regional land patterns capable of controlling local climates (such as mountains, lakes, etc.). To this end, any specific scenario used for regional impact assessment, although based on locally observed climatic features as specified above, must be viewed as only one of many physically plausible representations of climate change. Projections of precipitation are particularly uncertain. For these reasons, it is highly desirable to use several different scenarios within an assessment study, so that the vulnerability of current systems can be tested over a wide range of projected climate change.

In conclusion, we used a total of 5 climate scenarios, each composed of $44 \mathrm{yr}$. We will refer to each specifically as: (1) baseline; $(2,3)$ HCGS-2030 and CCGS2030; and $(4,5)$ HCGS-2090 and CCGS-2090.

\subsection{Crop models}

We used the DSSAT (Decision Support Systems for Agro-technology Transfer) family of crop-growth models to simulate plant development, growth and yield of wheat, maize, and potato (Tsuji et al. 1994). The model of Ben Mechlia \& Carrol (1989) was used to simulate citrus production.

The crop models used herein have been applied extensively to project crop yields across the US, under both current and climate change conditions, as well as to simulate crop response to elevated $\mathrm{CO}_{2}$ (for model equations and linkages among GCMs and crop simulations, see e.g. Rosenzweig et al. 1995, Tubiello et al. 1999). 
The inputs necessary to run the models were daily total solar radiation, daily minimum and maximum temperature, and daily precipitation. The crop models computed, in daily time-steps, plant phenological development from planting to harvest; photosynthesis and plant growth; carbon allocation to plant organs, including grain or fruit; and soil water and nitrogen movement. Additional inputs necessary to run the crop models at each site were soil type (depth, bulk density, and composition), plant characteristics (cultivar type, phase-specific development rates) and crop management (planting date, sowing depth, row space, irrigation, and fertilization type and schedules). We obtained such input data from the USDA agricultural extension officers near each simulation site.

Rainfed and irrigated crop production were simulated at each site. Irrigation was model-prescribed and computed as the amount of water necessary to re-fill the soil profile to a $30 \mathrm{~cm}$ depth, applied after $50 \%$ depletion of field capacity. Fertilizer applications were simulated to be non-limiting for plant growth. Finally, simulations were run sequentially, i.e. soil moisture at planting was computed each year by the model, as a function of previous weather, rather than prescribed as a fixed percentage of soil moisture.
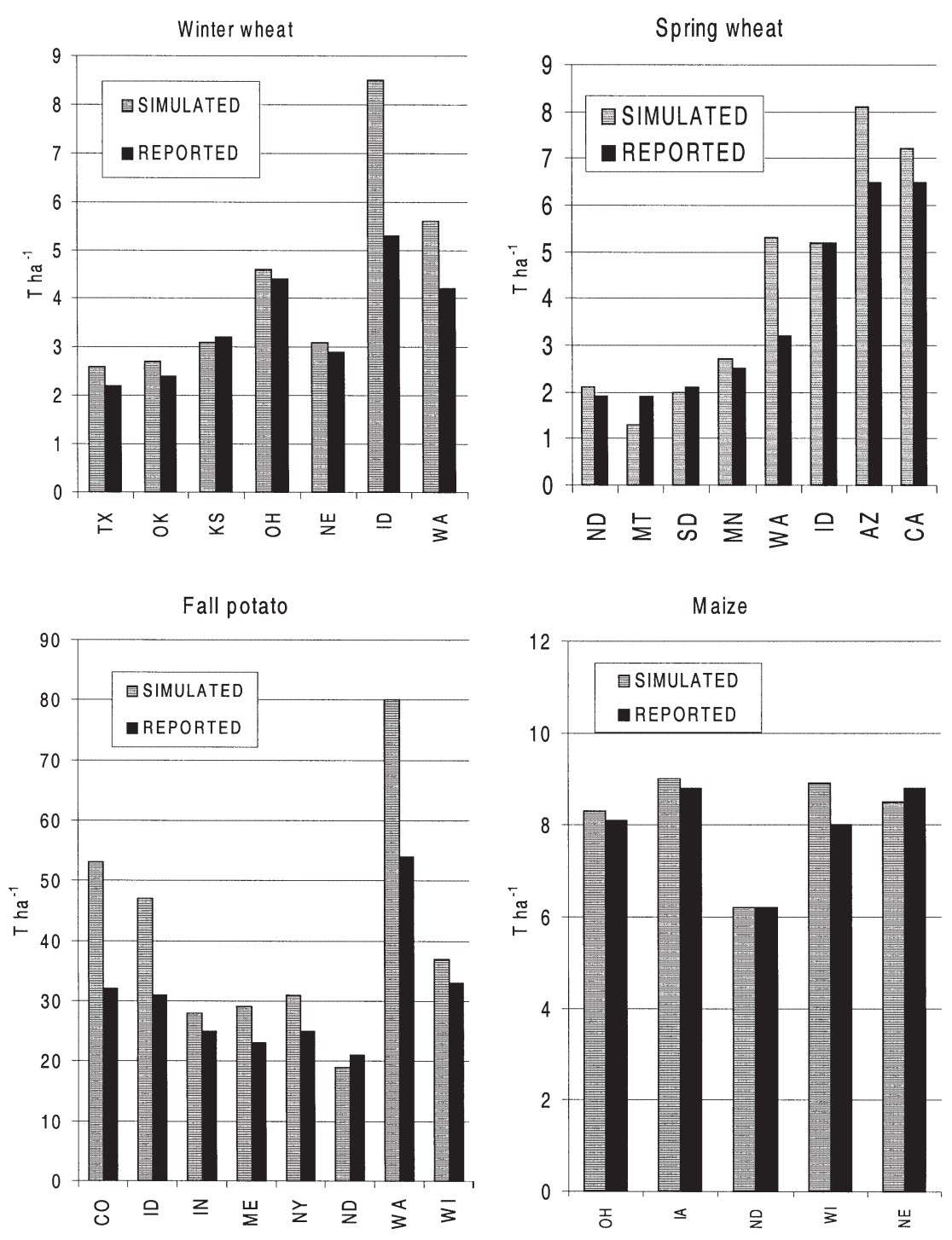

Fig. 3. Simulated vs observed crop yields under current climate. For each crop, irrigated and rainfed production was first aggregated at the county level, using percentage irrigated area from USDA statistics. Results are grouped by state for clarity

\section{SIMULATIONS UNDER CURRENT CLIMATE}

Model simulations of crop yield agreed within 20-25\% with USDA reported yield across the US states (Fig. 3). Percent model error (root mean square error of simulated vs observed yield, divided by mean observed yield) was 15-25\% across all crops. Coefficients of variation (CV) of yield, defined as the ratio of standard deviation over the mean, were computed over the entire time-series available at each site. The $\mathrm{CV}$ represented a measure of farmer's risk. Specifically, small CVs indicated stable year-to-year production, while high CVs denoted high interannual variability of yield. CVs computed for observed yields were $10-15 \%$ for irrigated production and $20-30 \%$ for rainfed production. Simulated CVs were higher, specifically 10-30\% under irrigated conditions and $30-50 \%$ for rainfed production. Finally, simulated yields were biased towards higher values than observed.

Both higher simulated CVs and positive model bias were a direct result of the assumed optimal crop growing conditions with respect to nitrogen, soil quality, and pest-weed interactions. As previously discussed, such assumptions resulted in higher yields and in larger climate sensitivity of the simulated crops compared to observed. Next we present simulation results for each crop. 


\subsection{Winter wheat}

Winter wheat was simulated at Abilene, TX; Boise, ID; Columbus, OH; Dodge City, KS; Topeka, KS; Goodland, KS; North Platte, NE; Oklahoma City, OK; and Spokane, WA. In agreement with observations, record irrigated yields were simulated at Boise, ID, with all remaining sites producing $4.5-5.5 \mathrm{t} \mathrm{ha}^{-1}$. CVs for irrigated production were $10-15 \%$, and for rainfed conditions $30-50 \%$, also in agreement with reported data. The largest impacts of irrigation over rainfed practice were at Boise, ID (>400\%), and Spokane, WA (150\%). The smallest gains with irrigation were at the wet sites, i.e. Columbus, $\mathrm{OH}$, and Topeka, KS.

\subsection{Spring wheat}

Spring and durum wheat are grown extensively in North and South Dakota and Montana, with some important production centers in the Northwest, California, and Arizona. A total of 8 sites of importance to US spring wheat production were chosen. Spring wheat was simulated at Boise, ID; Fargo, ND; Fresno, CA; Glasgow, MT; Pierre, SD; St. Cloud, MN; Spokane, WA; and Tucson, AZ. Simulated irrigated yields were $50-60 \%$ higher than rainfed, with lower year-to-year variability (CV). The simulated impacts of irrigation were large at Boise, ID, Spokane, WA, and Tucson, AZ, where irrigated yields were 100, 300 and $1000 \%$ higher than under rainfed conditions, respectively. In agreement with agricultural statistics, the highest irrigated yields, 7-8 $\mathrm{t} \mathrm{ha}^{-1}$, were simulated at Tucson, AZ, and Fresno, CA, with all remaining sites producing $3-5 \mathrm{t} \mathrm{ha}^{-1}$. CV for irrigated production were $10-20 \%$, and for rainfed production $40-50 \%$.

\subsection{Maize}

Simulated maize yields agreed within 20\% with reported county-level averages, with the highest dry- land yields, $>8 \mathrm{t} \mathrm{ha}^{-1}$, simulated at Columbus, $\mathrm{OH}_{\text {; }}$ Madison, $\mathrm{WI}_{\text {; }}$ and Indianapolis, IN. Production at the remaining sites was computed to be $5-7 \mathrm{t} \mathrm{ha}^{-1}$, with low yields and high CVs simulated at St. Cloud, MN, currently at the northern margin of the main US maize production area. CVs for irrigated production were $10-20 \%$, and for rainfed production $30-50 \%$.

\subsection{Potato}

We chose a total of 12 sites of importance to national potato production. Crop simulations were performed at Alamosa, CO; Boise, ID; Buffalo, NY; Caribou, ME; Fargo, ND; Indianapolis, IN; Madison, WI; Medford, OR; Muskegon, MI; Pendleton, OR; Scott Bluff, NE; and Yakima, WA. In agreement with agricultural statistics, continuous rainfed potato production was simulated as viable at Buffalo, NY; Caribou ME; Fargo, ND; Indianapolis, IN; and Madison, WI. Under the current climate, crop simulations agreed within $25 \%$ with reported production. The highest simulated irrigated yields, slightly $>80 \mathrm{t} \mathrm{ha}^{-1}$, were simulated at the northwestern sites, at Medford, OR; Pendleton, $\mathrm{OR}_{i}$ and Yakima, WA. The impact of irrigation was also the greatest at these sites (irrigated yields were about 10 times rainfed yields). At all the remaining sites production was between 40 and $50 \mathrm{t} \mathrm{ha}^{-1}$. CV for irrigated production were 6-9\%. They were 30-40\% under rainfed conditions.

\subsection{Citrus}

We simulated the effects of current and projected future climate on valencia oranges across the southern United States. We considered a total of 8 sites for our analysis of climate change effects, of which 4 sites (Bakersfield, CA; Corpus Christi, TX; Daytona Beach, FL; and Miami, FL) correspond to high-producing areas in the US, with simulated yields in agreement with observations, $>11 \mathrm{t} \mathrm{ha}^{-1}$ of fruit. One site (Red

Table 2. Summary of simulation results expressed as percent yield change from baseline (1951-1994) simulations. For each of 5 crops, intervals represent the range across simulated production sites

\begin{tabular}{|c|c|c|c|c|c|c|c|c|}
\hline \multirow[t]{3}{*}{ Crop } & \multicolumn{4}{|c|}{2030} & \multicolumn{4}{|c|}{2090} \\
\hline & \multicolumn{2}{|c|}{ HCGS } & \multicolumn{2}{|c|}{ CCGS } & \multicolumn{2}{|c|}{ HCGS } & \multicolumn{2}{|c|}{ CCGS } \\
\hline & Rainfed & Irrigated & Rainfed & Irrigated & Rainfed & Irrigated & Rainfed & Irrigated \\
\hline Winter wheat & +6 to +20 & +5 to +10 & -50 to -10 & +2 to +6 & +13 to +48 & +10 to +25 & -4 to -30 & +6 to +12 \\
\hline Spring wheat & +13 to +20 & -8 to +5 & +10 to +15 & -2 to -24 & +6 to +45 & -10 to +10 & -24 to -15 & -55 to -10 \\
\hline Maize & -1 to +24 & -7 to 0 & -5 to +25 & -15 to +10 & -1 to +50 & -6 to +6 & -14 to +25 & -20 to -5 \\
\hline Potato & -10 to +30 & -9 to +2 & -33 to +34 & -13 to -6 & +10 to +22 & -32 to +5 & -63 to -7 & -51 to -1 \\
\hline Citrus & & +6 to +47 & & -5 to +45 & & +18 to +65 & & +11 to +75 \\
\hline
\end{tabular}


Bluff, CA) represented mid-level production, around $7 \mathrm{t} \mathrm{ha}^{-1}$. Three sites (Tucson, AZ; Port Arthur, TX; and Las Vegas, NV), producing 4-6 $\mathrm{t} \mathrm{ha}^{-1}$, represented marginal production levels. Another additional 5 sites were chosen for simulations, to investigate potential for citrus expansion northward of the current production area. They were El Paso, TX; Montgomery, AL; Savannah, GA; Shreveport, LA; and Tallahassee, FL. Under the current climate, simulations at these latter sites yielded 2-2.5 $\mathrm{t} \mathrm{ha}^{-1}$.

\section{SIMULATION RESULTS UNDER CLIMATE CHANGE SCENARIOS}

Two sets of simulations were considered in this study for each scenario: with and without adaptation. The adaptation techniques we considered were simple farm-level techniques, easily available today, such as early planting, a realistic scenario for adaptation to climate change at many northern sites, and the use of cultivars better adapted to warmer climates than those currently grown at specific locations. Early planting was simulated for spring crops, to provide for heat and drought stress avoidance in the late summer months. Growth and yield of better heat-adapted cultivars were simulated for winter crops, such as wheat, by modifying the specific model parameters that control the length of the grain-filling period. By increasing the time to maturity, yield potential under climate change could be restored to levels typical of current conditions.

Our simulations could also be used to estimate the additional potential for adaptation arising from changes in irrigation management. Results of such analyses have been reported elsewhere (http://www.nacc.usgcrp. gov/sectors/agriculture/mccarl.pdf).

In the following sections, we first analyze rainfed and irrigated production without adaptation. (See Table 2 for a summary. As noted earlier, the interested reader will find complete output data at the US National Assessment website.) We then analyze the simulated effects of adaptation techniques, including a qualitative discussion on irrigation management.

\subsection{Winter wheat}

The 2 climate change scenarios considered in this study resulted in opposite re- sults for US wheat production, due to differences in projected precipitation: the CCGS scenario (drier) resulted in large negative to small positive impacts on harvest yields, while the Hadley scenario (wetter) generated positive outcomes (Fig. 4).

The higher temperatures projected under climate change were favorable to northern site production, but deleterious to southern sites. Increased precipitation in the Northwest and decreased precipitation in the Great Plains were the major factors controlling the response of wheat yields to the future scenarios considered in this study.

\subsubsection{Rainfed production}

The CCGS scenarios resulted in large negative impacts for both continuous and fallow production at all sites, including the major production centers in the Great Plains. Grain yields decreased $10-50 \%$ in 2030 and by $4-30 \%$ in 2090. At Dodge City, KS, Goodland, KS, and North Platte, NE, CV of yield consistently increased in both decades, suggesting increased risk

\section{CCGS \\ 2030s \\ HCGS}
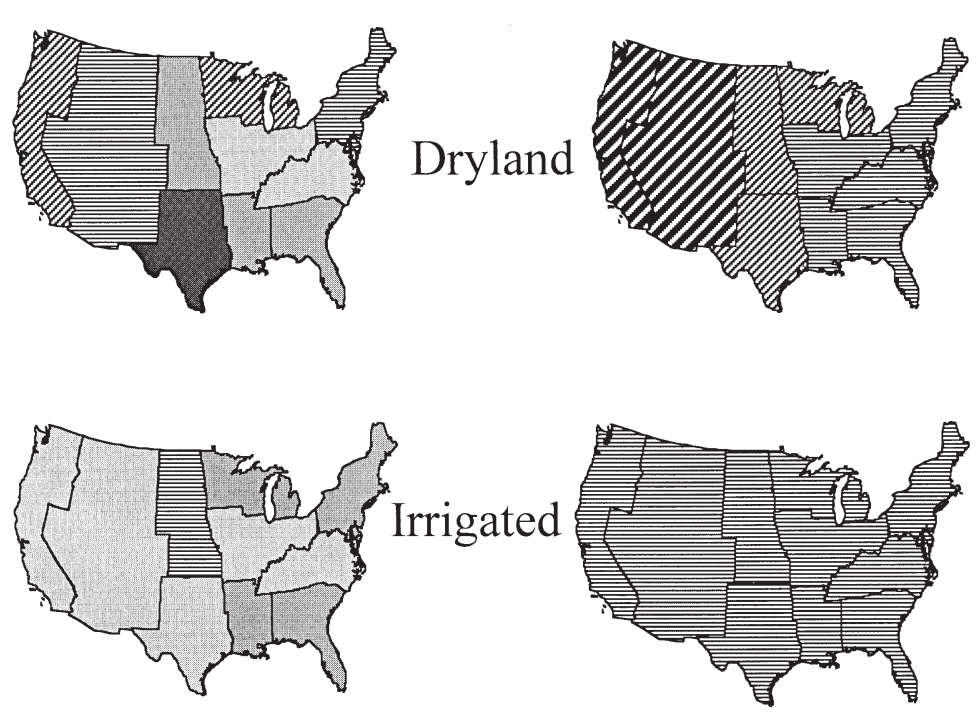

$$
\begin{aligned}
& \mathrm{CC}=\text { Canadian Center Model } \\
& \mathrm{HC}=\text { Hadley Center Model } \\
& \mathrm{GS}=\text { Greenhouse gases with } \\
& \text { sulfate aerosols } \\
& \text { Direct } \mathrm{CO}_{2} \text { effects included }
\end{aligned}
$$

Fig. 4. Projected changes in winter wheat yields under rainfed and irrigated conditions in 2030 as a function of climate change scenario 

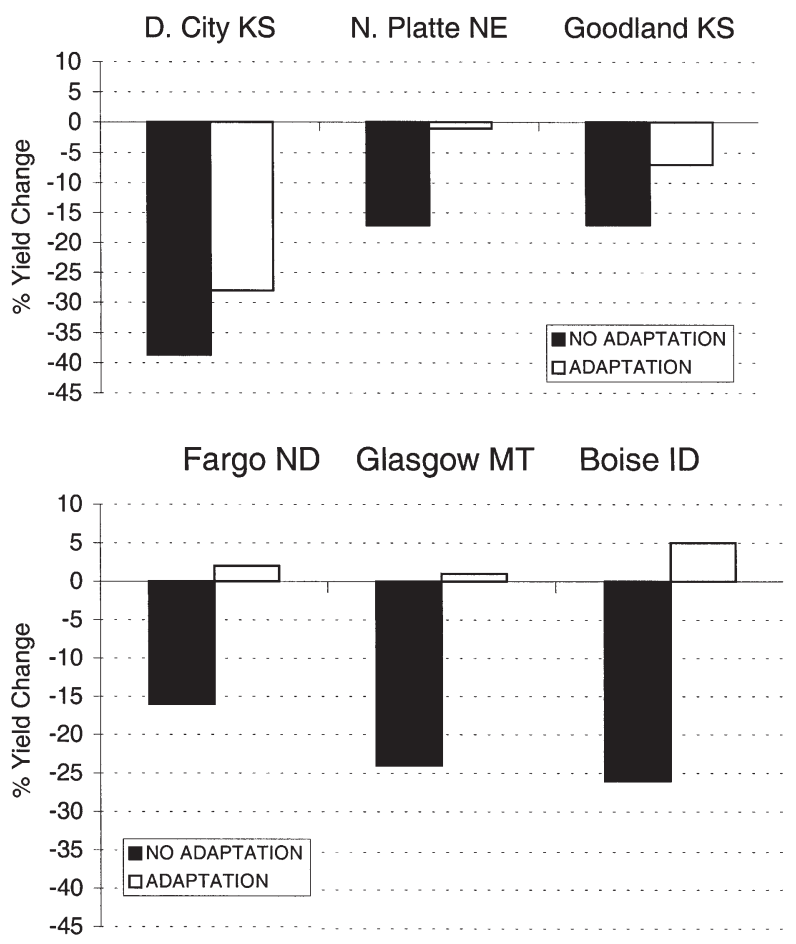

Fig. 5. Effects of adaptation techniques and their simulated impacts on projected yields. Top: effects of changing cultivar for winter wheat. Bottom: effects of early planting of spring wheat

to farmers. The exception for the CCGS scenario results was Columbus, OH, where yield increased 3-8\% in 2030 and $16-24 \%$ in 2090. The HCGS scenarios resulted in yield increases across all sites. Rainfed production increased $6-20 \%$ in 2030 and $13-48 \%$ in 2090. Year-to-year variation decreased at most sites.

\subsubsection{Irrigated production}

Irrigated wheat yields increased under both GCM scenarios, although increases were larger under the HCGS than under the CCGS projected climate change. In 2030, yield increases ranged between 2 and $10 \%$. In 2090, yields were 6-25\% greater than under current climate. Irrigation water use decreased by $10-40 \%$.

\subsubsection{Adaptation}

The positive crop simulation results implied no need to adapt current crop practices and water management of wheat production under the HCGS scenario. Under the CCGS scenario, however, adaptation techniques would be required to avoid the yield losses simulated in the Great Plains. Additionally, under the CCGS sce- nario simulated rainfed cultivation in Kansas was associated with very high CVs (>80\%).

Adaptation strategies in the Great Plains involved the simulation of cultivars better adapted to a warmer climate, requiring less vernalization, and with longer grain filling periods. As shown in Fig. 5, simulations with a southern-grown variety helped to counterbalance projected yield decreases at North Platte, NE. The same adaptation strategy did not work well for sites in Kansas and Oklahoma, however, due to the strong aridity projected by the CCGS model in this region.

\subsection{Spring wheat}

Higher temperatures significantly impacted spring wheat yields across sites, time horizon, and management practice, mainly by hastening crop development.

\subsubsection{Rainfed production}

In 2030, rainfed spring wheat production increased under both GCM scenarios by $10-20 \%$, due to increased precipitation and despite higher temperatures, with reduced CVs. These positive impacts on yield were also projected in 2090 under the HCGS scenario, with yield increases in the range $6-45 \%$. The largest increases were simulated at Pierre, SD (47\%).

The 2090 CCGS scenario resulted in significant decreases in spring wheat yields at current production sites. Yields decreased at Fargo, ND (-16\%), and Glasgow, MT $(-24 \%)$. Yield decreases were also projected in Fresno, CA (-20\%). By 2090, the CCGS-projected spring-summer temperatures were about $4^{\circ} \mathrm{C}$ higher than present at all sites, affecting wheat development and grain filling negatively, and depressing yields despite the gains due to precipitation increases.

\subsubsection{Irrigated production}

Irrigated spring wheat production decreased by $5-20 \%$ at 5 of the 8 sites considered, under both scenarios. In 2030, yields decreased at Boise, ID (-17 to $-7 \%)$, Spokane, WA ( -1 to $-4 \%$ ), Tucson, AZ ( -6 to $-3 \%$ ), and Fresno, CA $(-24$ to $-16 \%)$. The same negative results were computed at these sites in 2090, with the largest reduction simulated at Fresno, CA (-30 to $-45 \%)$.

Under every scenario and at all sites, irrigation water use decreased significantly, due to the accelerated growing period associated to warmer climate. By 2090, simulated yield reductions at all sites were in the range of $20-40 \%$, except at Fresno, CA, where they were $50-60 \%$. 


\subsubsection{Adaptation}

Simulated rainfed production increased significantly under all scenarios due to increased precipitation. For example, at Spokane, WA, and Boise, ID, currently major irrigated sites, current production levels could be maintained by shifting some irrigated land to rainfed production. In particular, under the CCGS scenario, rainfed yields simulated in 2090 under the CCGS scenario were comparable to those simulated in current conditions under irrigation.

At Fargo, ND, and Glasgow, MT, simulations of early planting by 2 to 3 wk maintained simulated yields at current levels (Fig. 5).

\subsection{Maize}

\subsubsection{Rainfed production}

Simulated dryland yields increased in response to the projected climate change. At all sites, increases in precipitation more than counterbalanced the otherwise negative effects of higher temperatures. Yield increases were computed at current major production sites: Des Moines, IA (15-25\%); Peoria, IL (15-38\%); and Sioux Falls, SD (8-35\%). Larger increases were simulated at northern sites: Fargo, ND (25-50\%); Duluth, MN (30-50\%); and St. Cloud, MN, where both higher temperatures and increased precipitation affected maize yields positively. Smaller yield changes were simulated at the remaining sites, in the range -5 to $+5 \%$.

\subsubsection{Irrigated production}

Irrigated yields decreased because of high temperature stress, in the range of -4 to $-20 \%$ at current production sites. By contrast, yields increased at northern sites of current marginal production. At St. Cloud, MN, due to an increase in the growing period associated with higher temperatures, simulated yields under the 2090 CCGS scenario were almost 3 times as high as current levels.

\subsubsection{Adaptation}

Additional simulations with early planting indicated that such adaptation strategy could be useful to counterbalance small negative yield decreases under climate change. In our simulations, dryland maize production became even more competitive over irrigation, with higher yields and decreased year-to-year variability.

\subsection{Potato}

Simulation results indicated a high sensitivity of yields to the projected higher winter temperatures.

\subsubsection{Rainfed production}

The 2 GCM scenarios considered in this study resulted in sizable gains in 2030. At 4 of the 5 sites considered, crop production increased on average by $20 \%$, except at Indianapolis, IN, where the CCGS scenario projected a $33 \%$ reduction, while the HCGS scenario resulted in a $7 \%$ increase. CVs for all sites generally decreased due to increased precipitation.

In 2090, the CCGS scenario resulted in large decreases at most sites, while under HCGS potato yields increased by 10-20\%, largely maintaining the gains projected in 2030. Under the CCGS scenario, rainfed production decreased on average by more than $20 \%$, with the smallest effects simulated at Madison, WI, and the largest at Indianapolis, IN $(-47 \%)$, and at Fargo, ND (-63\%). Under this scenario, large increases in temperature in 2090 counterbalanced the beneficial effects of increased precipitation.

\subsubsection{Irrigated production}

Irrigated yields generally decreased in 2030 in the range $1-10 \%$. The projected temperature increases affected crop production negatively. The CCGS scenario resulted in simulated yield reductions from -6 to $-13 \%$. Exceptions were found at Yakima, WA (+5\%). Under the HCGS scenario, yields decreased from -6 to $-8 \%$; however small increases $(2 \%)$ were simulated in Fargo, ND, and Yakima, WA. Both GCM scenarios projected 5\% yield increases at Caribou, ME.

Yield decreased were also projected in 2090 under both GCM scenarios. Potato yields decreased by $10 \%$ at 2 of the 3 major production sites in the Northwest, while water use increased by $10 \%$ on average. Both GCM scenarios resulted in larger decreases (30-40\%) at Boise, ID, and Scott Bluff, NE (27-50\%), and smaller ones at Pendleton, OR, Medford, OR (10-15\%), and Buffalo, NY (8-18\%).

\subsubsection{Adaptation}

Similar to the results obtained for other crops, the simulations suggested that rainfed production could become more competitive than irrigation, compared to current practices. Adaptation of cultivar did little to counterbalance the negative temperature effects com- 
puted in our simulations. Current potato production is mostly limited in the US to cultivars that need a period of cold weather for tuber initiation. Additional simulations performed with early planting helped increase yields somewhat, but not up to the levels simulated under current conditions. For example, anticipating planting by as much as 1 mo at Boise, ID, helped to reduce yield losses under climate change by $50 \%$, relative to simulations without adaptation.

\subsection{Citrus}

Simulated fruit production benefited greatly from the projected climate change. Yields increased 20-50\%, while irrigation water use decreased. Crop loss due to freezing was $65 \%$ lower on average in 2030 and $80 \%$ lower in 2090, at all sites. Of the main production sites considered in this study, Miami, FL, experienced small increases, in the range $6-15 \%$. Of the other 3 remaining major production sites, increases in the range $20-30 \%$ were projected in 2030 and in the range $50-70 \%$ in 2090 . Irrigation water use decreased significantly at Red Bluff, CA, Corpus Christi, TX, and Daytona Beach, FL. All sites experienced a decrease in $\mathrm{CV}$, due to the reduction of crop loss from freezing.

Simulated fruit yields increased in Tucson, AZ, and Las Vegas, NV. However, potential for northward expansion of US citrus production was simulated to be small. Simulations results indicated that in 2030 and 2090, under both CCGS and HCGS, northern sites of current marginal production continued to have lower fruit yield, higher risk of crop loss due to freezing, and lower water availability than the southern sites.

\section{DISCUSSION}

Several important factors affected the response of US crop yields under climate change in our simulations. We specifically analyzed effects of increased precipitation, increased temperature, and $\mathrm{CO}_{2}$ fertilization. To this extent, we summarized the large amount of data produced in this study into specific aggregate tables, as discussed below.

\subsection{Precipitation}

The 2 climate scenarios used in this assessment produced warmer and overall much wetter conditions over areas of major US rainfed cereal production, compared to the present, with few exceptions. For example, when averaged across all grain maize production sites and climate scenarios, growing season precipita- tion was projected to be $20 \%$ higher than present for the 2030s, and $23 \%$ higher in the 2090s (Table 3). When these averages were restricted to the major Maize Belt sites used in the study, these numbers increase to $22 \%$ in the 2030 s and $40 \%$ in the 2090 s. These precipitation increases were the significant factor leading to the projected rise in total national output as computed by the economic models, as rainfed cereal production is one of its major components.

Because GCM predictions of regional precipitation were quite poor, however, we argue that low significance should be given to crop predictions that strongly depend on uni-directional precipitation signals. In contrast, it was more useful to analyze those few cases where sharp differences in precipitation occurred among scenarios, so that potential vulnerability of future crop production could be better characterized. Perhaps the most significant of such cases was that of rainfed hard red winter wheat production in western Kansas, a key US Bread Basket region (Table 4). The HCGS scenario projected 3-17\% higher annual precipitation compared to the present for this region. Under such circumstances, simulated rainfed wheat production increased up to $30 \%$, averaged across time horizons. By contrast, under the CCGS scenario, which projected large decreases in precipitation (in the range $10-20 \%$ but as high as $-40 \%$ in the fall season), rainfed production was severely affected, with average yields decreasing by $30 \%$ or more. At the same time, inter-annual yield variability, an indicator of a farmer's risk, nearly doubled.

Table 3. Simulation summary for maize. Percentage yield changes from the baseline scenario due to climate change and elevated $\mathrm{CO}_{2}$, under rainfed and irrigated conditions. The third column indicates changes in daily precipitation during the crop growing period

\begin{tabular}{|lccc|}
\hline & Rainfed & Irrigated & Precipitation $\mathrm{d}^{-1}$ \\
\hline $2030 \mathrm{~s}$ & 11 & -6 & 20 \\
2090s & 15 & -8 & 23 \\
ALL & 13 & -7.5 & 21.5 \\
\hline
\end{tabular}

Table 4. Simulation summary for rainfed winter wheat in western Kansas. Percentage yield changes from the baseline scenario due to climate change and elevated $\mathrm{CO}_{2}$, under rainfed conditions. The second column indicates changes in growing season precipitation

\begin{tabular}{|lcc|}
\hline & Rainfed & Precipitation \\
\hline HCGS & +30 & +20 \\
CCGS & -35 & -30 \\
\hline
\end{tabular}




\subsection{Temperature}

Effects of precipitation and temperature were separated in part by comparing at each site the effects of the climate scenarios on rainfed and irrigated production, the latter being insensitive to precipitation changes. Using US maize as an example, rainfed production averaged across sites and scenarios increased $11 \%$ in the $2030 \mathrm{~s}$, while irrigated production decreased by $6 \%$. In the 2090 s, rainfed production was $15 \%$ higher than present, while irrigated production decreased $8 \%$.

Similar calculations with all crops simulated in this study confirmed that higher temperatures alone negatively affected US yields, in particular at southern sites, where current temperatures are already high. The only exception was computed at northernmost latitudes, where a lengthening of the growing season was beneficial to crop growth.

\subsection{Strength of $\mathrm{CO}_{2}$ fertilization effects}

The magnitude and sometimes even the direction of climate change effects on crop yields depended on the simulated strength of the $\mathrm{CO}_{2}$ response (Fig. 6). Our

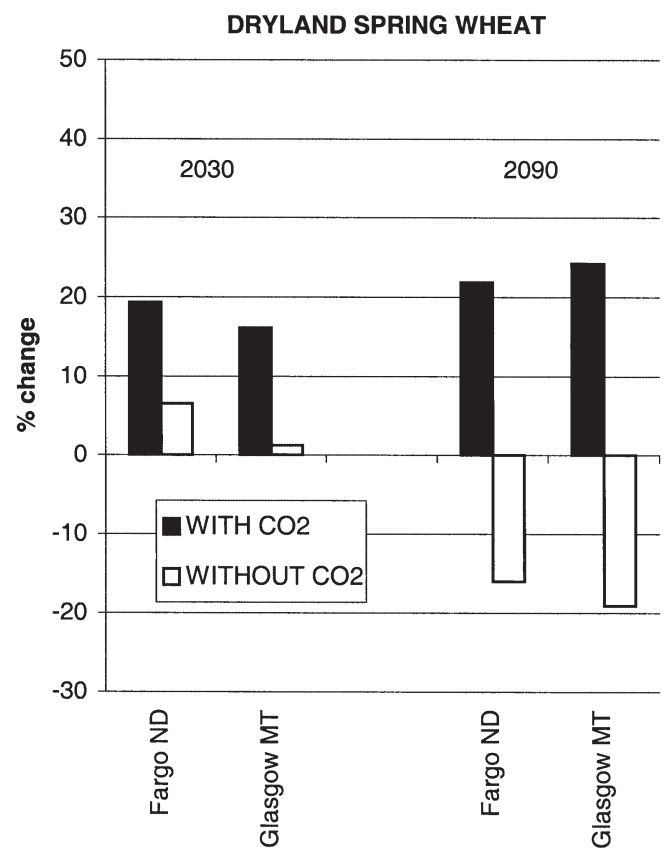

Fig. 6. Changes in magnitude and direction of simulated yields in response to climate change, as a function of the assumed strength of the $\mathrm{CO}_{2}$ fertilization. The simulated $\mathrm{CO}_{2}$ plant response results in increased crop growth and yield. Such stimulation can either reinforce positive effects of climate change on spring wheat (2030) or help counterbalance negative climatic effects on crop yield (2090)
Table 5. Simulation summary for maize and wheat. Percentage yield changes from the baseline scenario due to climate change without and with fertilization due to elevated $\mathrm{CO}_{2}$, averaged across time horizons and GCM scenarios

\begin{tabular}{|lcc|}
\hline & Rainfed & Irrigated \\
\hline Without $\mathrm{CO}_{2}$ & 0.3 & -12 \\
With $\mathrm{CO}_{2}$ & 13 & -7.5 \\
\hline
\end{tabular}

crop models employed state-of-the-art parameterizations to simulate the $\mathrm{CO}_{2}$ fertilization effect on crop growth. These formulations were nonetheless largely based on controlled-environment studies. They should therefore be regarded as providing an upper limit to the potential response in the field, where, in contrast to clean experimental settings, a variety of additional mechanisms, including resource competition, plantpest interactions, and soil limitations, will likely limit crop response to elevated $\mathrm{CO}_{2}$ (Tubiello et al. 1999). What if such responses were much smaller than assumed in the models? Table 5 shows, as an example, the effects of climate change on aggregated maize and wheat yields, with and without $\mathrm{CO}_{2}$ fertilization. Under rainfed conditions and no simulated $\mathrm{CO}_{2}$ response, yields averaged across sites, scenarios, and time horizons remained virtually unchanged $(+0.3 \%)$. They increased $(+13 \%)$ only with $\mathrm{CO}_{2}$ fertilization. Similarly, under irrigated conditions, grain yields averaged across sites and scenarios decreased significantly more with no $\mathrm{CO}_{2}$ response $(-12 \%)$ than with $\mathrm{CO}_{2}$ fertilization $(-7.5 \%)$. Overall analyses including all crop results suggest that precipitation and elevated $\mathrm{CO}_{2}$ each contributed about half of the yield increases simulated in this study.

\section{CONCLUSIONS}

We analyzed and discussed new simulation results of the projected impacts of climate change on US agriculture. Specifically, we showed the importance of using different climate scenarios in order to assess system vulnerability over key crop-producing regions, especially given the high uncertainty in projected precipitation change. For instance, we computed that winter wheat production would slightly increase under the HCGS scenario, but that it could be reduced by $30-40 \%$ under the CCGS scenario.

We investigated the role of simple adaptation techniques in minimizing negative climate impacts on crop yields. In the northern plains, under the CCGS 2090 scenario, early planting fully counterbalanced negative impacts of climate change, while no adaptation 
resulted in 20-25\% yield reductions. In the Pacific Northwest, early planting helped to reduce projected losses in potato production by $50 \%$. Not all adaptation techniques considered in this study successfully counterbalanced the projected negative climatic effects. In Kansas, a key Bread Basket region, the use of winter wheat cultivars better adapted to warm climates did not improve simulation results.

We analyzed the importance of crop response to elevated $\mathrm{CO}_{2}$ under climate change. It is still uncertain whether $\mathrm{CO}_{2}$ fertilization will be as strong in agricultural fields as suggested under controlled experiments. At simulation sites in the Great Plains, for instance, maize yield changes ranged between -30 and $+20 \%$ compared to the present, depending on the assumed strength of the simulated $\mathrm{CO}_{2}$ response.

Finally, we simulated the potential effects of climate change on US crop production within the research framework provided by the US National Assessment study. Although model results suggested that current US food production systems will not be at risk in this century, we underlined the importance of analyzing regional production differences within the US, showing some areas losing comparative advantage to other regions. The regional results showed broadly that climate change favors northern areas and can worsen conditions in southern areas, in agreement with many previous studies.

Acknowledgements. The authors would like to thank John Reilly for continued support during the US National Assessment study. This work was funded under UCAR Project Grant S99-14846 to Columbia University. Support from NASA-GISS to F.N.T., C.R. and R.A.G. helped to provide for office space and computational facilities.

\section{LITERATURE CITED}

Adams RM, Rosenzweig C, Peart RM, Ritchie JT and 6 others (1990) Global climate change and U.S. agriculture: an interdisciplinary assessment. Nature 345:219-224

Ben Mechlia N, Carrol JJ (1989) Agroclimatic modeling for the simulation of phenology, yield, and quality of crop production. 1. Citrus response formulation. Int J Biometeorol 33:36-51

Chaudhuri UN, Kirkam MB, Kanemasu ET (1990) Root growth of winter wheat under elevated carbon dioxide and drought. Crop Sci 30:853-857

Curry RB, Jones JW, Boote KJ, Peart RM, Allen LH Jr (1995)

Editorial responsibility: Robert Davis,

Charlottesville, Virginia, USA
Response of soybeans to predicted climate change in the USA. In: Rosenzweig C, Allen LH Jr, Jones JW, Tsuji GY, Hildebrand $\mathrm{P}$ (eds) Climate change and agriculture: analysis of potential international impacts. ASA Spec Publ No. 59, American Society of Agronomy, Madison, WI, p 163-181

Easterling WE III, Crosson PR, Rosenberg NJ, McKenny MS, Katz LA, Lemon L (1993) Agricultural impacts of and response to climate change in the Missouri-IowaNebraska-Kansas (MINK) region. Clim Change 24:23-61

Houghton JT, Meira Filho LG, Callander BA, Harris N, Kattenberg A, Maskell K (eds) (1996) IPCC climate change 1995: the science of climate change. Cambridge University Press, Cambridge

Kimball BA (1983) Carbon dioxide and agricultural yield: an assemblage and analysis of 430 prior observations. Agron J 75:779-786

Kimball BA, Pinter PJ Jr, Garcia RL, LaMorte RL and 5 others (1995) Productivity and water use of wheat under free-air $\mathrm{CO}_{2}$ enrichment. Global Change Biol 1:429-442

Mearns LO, Rosenzweig C, Goldberg R (1997) Mean and variance change in climate scenarios: methods, agricultural applications, and measures of uncertainty. Climatic Change 35:367-396

Reilly J, Tubiello FN, McCarl B, Melillo J (2001) Climate change and agriculture in the United States. In: Melillo J, Janetos G, Karl T (eds) Climate change impacts on the United States: foundation, USGCRP. Cambridge Universtiy Press, Cambridge, p 379-403

Rosenberg NJ (1993) Towards an integrated assessment of climate change: the MINK study. Clim Change 24:1-175

Rosenzweig C, Hillel D (1998) Climate change and the global harvest. Oxford University Press, Oxford

Rosenzweig C, Parry ML (1994) Potential impact of climate change on world food supply. Nature 367:133-138

Rosenzweig C, Tubiello FN (1997) Impacts of future climate change on Mediterranean agriculture: current methodologies and future directions. Mitig Adapt Strat Clim Change $1: 219-232$

Rosenzweig C, Ritchie JT, Jones JW, Tsuji GY, Hildebrand P (1995) Climate change and agriculture: analysis of potential international impacts. ASA Spec Publ No. 59, American Society of Agronomy, Madison, WI

Sionit N, Mortensen DA, Strain BR, Hellmers H (1981) Growth response of wheat to $\mathrm{CO}_{2}$ enrichment and different levels of mineral nutrition. Agron J 73:1023-1027

Tsuji GY, Uehara G, Balas S (eds) (1994) DSSAT v3. University of Hawaii, Honolulu

Tubiello FN, Rosenzweig C, Kimball BA, Pinter PJ Jr, Wall GW, Hunsaker DJ, Lamorte RL, Garcia RL (1999) Testing CERES-wheat with FACE data: $\mathrm{CO}_{2}$ and water interactions. Agron J 91:1856-1865

US National Assessment (2000) The potential consequences of climate variability and change. Overview document. National Assessment Synthesis Team, US Global Climate Change Research Program, Washington, DC

Submitted: December 23, 2000; Accepted: July 5, 2001

Proofs received from author(s): February 26, 2002 